\title{
A Population-based Study of Intensive Care Unit Admissions in Rheumatoid Arthritis
}

\author{
Christine A. Peschken, Carol A. Hitchon, Allan Garland, Charles N. Bernstein, Hui Chen, \\ Randy Fransoo, and Ruth Ann Marrie
}

\begin{abstract}
Objective. We aimed to determine the incidence of and mortality after critical illness in rheumatoid arthritis (RA) compared with the general population, and to describe the risks for and characteristics of critical illness in patients with RA.

Methods. We used population-based administrative data from the Data Repository at the Manitoba Centre for Health Policy from 1984 to 2010, and linked clinical data from an intensive care unit (ICU) database to identify all persons with RA in the province requiring ICU admission. We identified a population-based control group, matched by age, sex, socioeconomic status, and region of residence. The incidence of ICU admission, reasons for, and mortality after ICU admission were compared between populations using age- and sex-standardized rates, rate ratios, Cox proportional hazards models, and logistic regression models.

Results. We identified 10,078 prevalent and 5560 incident cases of RA. After adjustment, the risk for ICU admission was higher for RA (HR 1.65, 95\% CI 1.50-1.83) versus the matched general population. From 2000-2010, the annual incidence of ICU admission among prevalent patients was about $1 \%$ in RA, with a crude 10 -year incidence of $8 \%$. Compared with the general population admitted to ICU, 1 year after ICU admission, mortality was increased by $40 \%$ in RA. Cardiovascular disorders were the most common reason for ICU admission in RA.

Conclusion. Patients with RA have a higher risk for admission to the ICU than the general population and increased mortality 1 year after admission. Even with advances in management, RA remains a serious disease with significant morbidity. (First Release December 1 2015; J Rheumatol 2016;43:26-33; doi:10.3899/jrheum.150312)
\end{abstract}

Key Indexing Terms:

RHEUMATOID ARTHRITIS CRITICAL ILLNESS ADMINISTRATIVEDATA INCIDENCE

From the Department of Internal Medicine, and Department of Community Health Sciences, and Manitoba Centre for Health Policy, and the IBD Clinical and Research Centre, University of Manitoba, Winnipeg, Manitoba, Canada.

Funded by grants from the Manitoba Health Research Council, the Health Sciences Centre Foundation and Research Department, and the Canadian Institutes of Health Research.

C.A. Peschken, MD, MSc, FRCPC, Associate Professor, Department of Internal Medicine, and Department of Community Health Sciences, University of Manitoba; C.A. Hitchon, MD, MSc, Department of Internal Medicine, University of Manitoba; A. Garland, MD, MA, Department of Internal Medicine, and Department of Community Health Sciences, and Manitoba Centre for Health Policy, University of Manitoba;

C.N. Bernstein, MD, Department of Internal Medicine, and IBD Clinical and Research Centre, University of Manitoba; H. Chen, MSc, Manitoba Centre for Health Policy, University of Manitoba; R. Fransoo, PhD, Department of Community Health Sciences, and Manitoba Centre for Health Policy, University of Manitoba; R.A. Marrie, MD, PhD. Department of Internal Medicine, and Department of Community Health Sciences, University of Manitoba.

Address correspondence to Dr. C.A. Peschken, Associate Professor, Departments of Medicine and Community Health Sciences, University of Manitoba, RR149 Arthritis Centre, 800 Sherbrook St., Winnipeg, Manitoba R3A1M4, Canada.E-mail: christine.peschken@umanitoba.ca

Full Release Article. For details see Reprints/Permissions at jrheum.org Accepted for publication September 14, 2015.
Rheumatoid arthritis (RA) is a chronic autoimmune, inflammatory arthropathy affecting $0.5-1.0 \%$ of the Canadian population ${ }^{1}$. Comorbidity and mortality are markedly increased in $\mathrm{RA}^{2,3,4}$, leading to high healthcare use ${ }^{5,6}$ that increases with increasing disease severity ${ }^{7}$ and accumulation of comorbidities ${ }^{8,9}$. Cardiovascular disease (CVD) and infections are the leading causes of morbidity and mortality in $\mathrm{RA}^{10,11,12,13,14,15,16,17,18}$. Patients with RA have a 2 -fold higher risk of myocardial infarctions compared with patients without $\mathrm{RA}^{10,11}$, and CVD is the most common cause of excess mortality in $\mathrm{RA}^{12}$. The risk of serious infections leading to critical illness requiring intensive care unit (ICU) admission is of particular interest because aggressive immunomodulating therapies are increasingly used earlier in the disease ${ }^{14,19}$ and increase the risk of infection ${ }^{20,21}$.

There is a paucity of knowledge about critical illness in RA, with prior studies reporting up to one-third of hospitalized patients with rheumatic disease requiring ICU care. However, these studies combined multiple autoimmune rheumatic diseases [primarily RA, followed by systemic lupus erythematosus (SLE) and systemic sclerosis] $]^{22,23}$,

Personal non-commercial use only. The Journal of Rheumatology Copyright $($ C 2016. All rights reserved. 
although these diseases have differing courses and potential causes of ICU admissions $23,24,25,26$. While these studies list worsening of underlying disease as a common reason for ICU admission ${ }^{23}$, patients with RA are most often hospitalized for other systemic medical or surgical conditions or complications from the treatment of $\mathrm{RA}^{22}$.

We hypothesized that persons with RA would have an increased risk of ICU admission, and that CVD and infections would be the most common reasons for ICU admission. Using a large, population-based dataset, we evaluated the incidence of ICU admission and mortality after ICU admission among persons with RA, and compared these outcomes with those in the general population. We also described the type and severity of critical illness in these populations.

\section{MATERIALS AND METHODS}

Administrative data. Our study used population-based administrative data housed in the data repository at the Manitoba Centre for Health Policy from April 1, 1984, to March 31, 2010, from Manitoba, a central Canadian province with a population of 1.2 million. The entire population is covered by a universal health insurance plan without required premiums ${ }^{27}$. All hospital, physician, and prescription claims are identified at the time of service. A population registry identifies when an individual moves into or out of Manitoba, or dies.

Critical illness dataset. We defined critical illness as admission to any of the 12 high-intensity adult ICU in Manitoba providing comprehensive critical care services ${ }^{28}$. The Winnipeg Regional Health Authority ICU database contains $>50,000$ records with detailed clinical information on every patient admission since 1999 to 11 of the 12 adult ICU in Manitoba, representing 93\% of adult ICU care in Manitoba with data prospectively collected by trained abstractors. The ICU database has been previously merged with the population health database using the provincial unique personal identification number ${ }^{29,30}$. Thus, the linkage of these 2 databases was used to identify ICU admissions and provides detailed information about health and healthcare use before, during, and after an ICU admission. Identified information included the Acute Physiology and Chronic Health Evaluation II score $(\mathrm{APS})^{31}$, Glasgow Coma Score $(\mathrm{GCS})^{32}$, the use of life support measures within the initial 2 days of ICU admission (mechanical ventilation, intravenous vasoactive agents, renal dialysis), length of stay, and the reasons for ICU admission (up to 6 recorded). We reviewed clinical data for ICU admissions in our incident cohorts from 2000 through 2010.

Study population. Manitobans with RA were identified using a validated administrative case definition ${ }^{33}$. Manitobans who resided in the province for $\geq 2$ years were identified as having RA if they had $\geq 5$ physician visits or hospitalizations with International Classification of Diseases-9-Clinical Modification (ICD-9-CM)/ICD-10 codes 714/M05, M06 recorded. Persons resident for $<2$ years were identified as having RA if they had $\geq 3$ such claims.

Validation studies by linkage with a clinical database resulted in a sensitivity of $77.12 \%$ and specificity of $90.30 \%$ for this definition.

All identified cases of RA were included in our prevalent cohorts. Incident cases were identified using the first recorded health claim for RA as the date of diagnosis (index date) for that person. Previous work has demonstrated the need for a lengthy run-in period to identify incident cases using administrative data ${ }^{34}$; therefore we excluded individuals with relevant claims during a 5 -year run-in period before the index date. Since administrative data began in 1984, the first year in which an incident case could be identified was 1989.

As a control group, we identified a matched general population cohort. Matching was based on sex, exact year of birth where possible (or within 5 yrs if exact matches not possible), and region of residence based on the 6-digit postal code. Statistical efficiency is optimized at 4-6 controls; therefore we obtained up to 5 controls for each case. We excluded individuals with RA and related diseases such as SLE, psoriatic arthritis, and the spondyloarthropathies. Because this was part of a larger study ${ }^{35,36}$, we excluded individuals with diagnostic codes for demyelinating disease and inflammatory bowel disease (Supplementary Table 1 available online at jrheum.org). Controls were assigned the same index date as their incident-matched case and were all alive on the index date.

Incidence of critical illness. The incidence of critical illness, as measured by the first ICU admission, was estimated separately in persons with prevalent and incident RA. The incidence of ICU admission among the prevalent RA cohort was estimated during the 10-year period of 2000/01-2009/10, and a new matched cohort was extracted from the general population for each year. The 10-year cumulative incidence of ICU admission for this period was estimated and age- and sex-standardized to the 2007 Canadian population. We compared the incidence of ICU admission between the RA and matched cohorts using incidence rate ratios (IRR) and calculated $95 \%$ CI by bootstrapping.

We used survival analysis to estimate the incidence of ICU admission for incident cohorts. The time from the index date to the first ICU admission among the RA and general population cohorts was compared using Kaplan-Meier analysis and log-rank tests. Persons not admitted to the ICU were censored as of death, migration out of Manitoba, or the end of the study period (March 31, 2010), whichever came first.

Table 1. Characteristics of the incident RA cohort and general population controls at the index (diagnosis) date. Values are n (\%) unless otherwise specified.

\begin{tabular}{lccc}
\hline Characteristic & $\begin{array}{c}\text { General Population } \\
\text { Controls, } \mathrm{n}=24,800\end{array}$ & $\begin{array}{c}\mathrm{RA}, \\
\mathrm{n}=5560\end{array}$ & $\mathrm{p}$ \\
\hline $\begin{array}{l}\text { Female } \\
\text { Age at diagnosis, }\end{array}$ & $17,834(71.9)$ & $4069(73.2)$ & 0.06 \\
$\quad$ yrs, mean (SD) & $53.4(17.9)$ & $54.1(17.6)$ & 0.0082 \\
Duration of followup & & & \\
$\quad$ from the index date, & & & \\
$\quad$ yrs, mean (SD) & $8.69(5.9)$ & $8.85(5.7)$ & 0.066 \\
Region of residence & & & \\
Urban & $13,195(56.1)$ & $3123(56.2)$ & 0.066 \\
$\quad$ Rural & $10,885(43.9)$ & $2437(43.8)$ & \\
Socioeconomic status & & & \\
Rural 1, lowest rural & $2215(8.93)$ & $565(10.2)$ & 0.0015 \\
Rural 2 & $2186(8.81)$ & $502(9.03)$ & \\
Rural 3 & $2406(9.70)$ & $514(9.24)$ & \\
Rural 4 & $2172(8.76)$ & $461(8.29)$ & \\
Rural 5, highest rural & $1730(6.98)$ & $369(6.64)$ & \\
Urban 1, lowest urban & $2912(11.7)$ & $685(12.3)$ & \\
Urban 2 & $3020(12.2)$ & $721(13.0)$ & \\
Urban 3 & $3012(12.1)$ & $660(11.8)$ & \\
Urban 4 & $2613(10.5)$ & $541(9.73)$ & \\
Urban 5, highest urban & $2042(8.23)$ & $469(8.43)$ & \\
$\quad$ Not calculated* & $492(1.98)$ & $73(1.31)$ & \\
Modified Charlson Comorbidity Index & & \\
0 & $23,020(92.3)$ & $4762(85.6)$ & $<0.0001$ \\
1 & $521(2.10)$ & $477(8.58)$ & \\
$>1$ to 3 & $1004(4.05)$ & $275(4.95)$ & \\
$>$ 3 to 5 & $107(0.43)$ & $25(0.45)$ & \\
$>$ 5 & $148(0.60)$ & $21(0.38)$ & \\
\hline
\end{tabular}

* People living where the Canadian census does not calculate an average household income, most of whom reside in nursing homes or other chronic care facilities. RA: rheumatoid arthritis.

Personal non-commercial use only. The Journal of Rheumatology Copyright (c) 2016. All rights reserved. 
For the multivariable analysis, we used a Cox proportional hazards model where the outcome was the first ICU admission after the index date, the exposure of interest was the cohort (RA or general population), and the model covariates were age at diagnosis, sex, comorbidity, year of RA diagnosis, and socioeconomic status (SES). SES was divided into quintiles based on average household income in the postal code of residence by linkage to census data, separately for rural and urban residence. A modified version of the Charlson Comorbidity Index (mCCI) was used as a measure of comorbidity. The CCI has been extensively used with administrative data and predicts health outcomes in patients admitted to the $\mathrm{ICU}^{37}$. The index was modified to exclude rheumatologic disease; we also collapsed the categories of diabetes with and without chronic complications because this distinction was inaccurate in Manitoba before $2006^{29}$, and the human immunodeficiency virus/AIDS category was not included because of small numbers. The mCCI was calculated based on hospital discharge ICD-9-CM/ICD-10 codes and using a 5-year look-back period because this improved the prediction of outcomes associated with comorbidity ${ }^{38}$. For the Cox regression analysis, we used time-dependent covariates, updated at 5-year intervals, to account for possible temporal changes in SES and comorbidity. The Cox proportional hazards assumption was tested using time-varying covariates and graphical methods.

Mortality. For the first ICU admissions among persons with RA and their controls, we estimated age- and sex-standardized mortality rates in the ICU, in the hospital, 30 days, and 1 year after ICU admission.

Characteristics of critical illness in incident cohorts. The primary reason for ICU admission was independently categorized by 2 reviewers $(\mathrm{CP}, \mathrm{CH})$ based on the admission diagnoses. ICU admission diagnoses were categorized as (1) infection, (2) ischemic heart disease (IHD), and (3) other acute serious illnesses ${ }^{39}$. Within IHD, we included myocardial infarctions, unstable angina, acute coronary insufficiency, and angioplasty or coronary artery bypass grafting. Arrhythmias, valve replacement surgery, and congestive heart failure without documentation of IHD were included under other diseases of the circulatory system. ICU admissions related to joint replacement surgery were also identified. Disagreements were resolved by consensus. We report frequency (percent) for categorical variables and mean (SD) or median (interquartile range) for continuous variables. We compared the characteristics of critical illness across the 2 cohorts using chi-square tests for categorical variables and Student $t$ tests or Kruskal-Wallis tests for continuous variables.

Using multivariable logistic regression, we compared the risk of being admitted for (1) infection and (2) ischemic CVD for the RA and general population cohorts, adjusting for age at ICU admission, sex, SES, comorbidity, year of ICU admission, and disease duration. Finally, we included the use of drug therapies, such as corticosteroids, immunomodulatory, and immunosuppressive drugs (Supplementary Table 2 available online at jrheum.org), in the year prior to admission (yes vs no) in the models of infection and CVD. Biologic therapies were first available in the region in 2000 ; by 2010 , only $\sim 15 \%$ of patients with prevalent RA were receiving these, therefore sample size did not allow separate analysis ${ }^{33}$. We report OR and $95 \% \mathrm{CI}$ for the association between disease cohort and reason for admission.

Our study was approved by the University of Manitoba Health Research Ethics Board and the Manitoba Health Information Privacy Committee. Statistical analyses were conducted using SAS V9.2 (SAS Institute Inc.).

\section{RESULTS}

ICU admission in prevalent cohorts. From 1984 to 2010, we identified 10,078 persons with RA. At the time of the first health claim for RA, the mean (SD) age of the RA cohort was 53.8 (18.6) years (median 56 yrs) and $72.9 \%$ were women. From these cohorts, the number of persons with RA living in Manitoba in each year from 2000/01-2009/10 varied from 4994 to 6225 for a prevalence rate ranging from $0.34 \%$ to $0.65 \%$.
Table 2. Multivariate Cox model of adjusted HR and 95\% CI for the association of RA and time to first intensive care unit admission.

\begin{tabular}{|c|c|c|}
\hline Characteristic & HR & $95 \% \mathrm{CI}$ \\
\hline \multicolumn{3}{|l|}{ Population } \\
\hline General population, reference & 1.0 & \\
\hline RA & 1.65 & $1.50-1.83$ \\
\hline \multicolumn{3}{|l|}{ Sex } \\
\hline Male, reference & 1.0 & \\
\hline Female & 0.51 & $0.48-0.55$ \\
\hline \multicolumn{3}{|l|}{ Age group, yrs } \\
\hline$<40$, reference & 1.0 & \\
\hline $40-59$ & 4.72 & $4.09-5.45$ \\
\hline$\geq 60$ & 13.30 & $11.54-15.32$ \\
\hline \multicolumn{3}{|l|}{ Socioeconomic status } \\
\hline Rural 1, lowest rural & 1.04 & $0.85-1.27$ \\
\hline Rural 2 & 0.81 & $0.66-0.99$ \\
\hline Rural 3 & 0.76 & $0.62-0.92$ \\
\hline Rural 4 & 1.08 & $0.89-1.31$ \\
\hline Rural 5, highest rural & 0.93 & $0.75-1.16$ \\
\hline Urban 1 , lowest urban & 1.68 & $1.43-1.98$ \\
\hline Urban 2 & 1.54 & $1.30-1.81$ \\
\hline Urban 3 & 1.33 & $1.12-1.56$ \\
\hline Urban 4 & 1.19 & $1.00-1.42$ \\
\hline Urban 5, highest urban, reference & 1.0 & \\
\hline Not calculated & 0.40 & $0.28-0.57$ \\
\hline \multicolumn{3}{|l|}{ Modified Charlson Comorbidity Index } \\
\hline 0 & 1.0 & \\
\hline 1 & 1.40 & $1.21-1.62$ \\
\hline$>1-3$ & 1.50 & $1.33-1.70$ \\
\hline$>3$ & 1.10 & $0.87-1.39$ \\
\hline \multicolumn{3}{|l|}{ Yr of RA diagnosis } \\
\hline 1989-93 & 1.0 & \\
\hline 1994-98 & 0.86 & $0.78-0.94$ \\
\hline $1999-03$ & 0.64 & $0.57-0.71$ \\
\hline $2004-10$ & 0.60 & $0.51-0.70$ \\
\hline
\end{tabular}

RA: rheumatoid arthritis.

Each year, more than $1 \%$ of persons with RA were admitted to an ICU with a crude 10-year average annual incidence of $1.26 \%$ (95\% CI 1.16-1.35). When standardized for age and sex, the average annual incidence of ICU admission was higher in the RA population compared with the general population (Figure 1A). The average annual incidence of ICU admission increased with age in both populations, but compared with the age-matched general population, the relative risk of ICU admission was highest in the youngest patients with RA (Figure 1B).

The crude 10-year cumulative incidence of ICU admission was 9.37\% (95\% CI 8.67-10.1) in RA compared with 5.36\% (95\% CI 5.25-5.47) in the general population. After age- and sex-standardization, the 10-year cumulative incidence of ICU admission was 7.68\% (95\% CI 7.04-8.32) in RA compared with $4.73 \%$ (95\% CI $4.62-4.83)$, IRR $1.62(95 \%$ CI $1.45-1.80)$.

ICU admission in incident cohorts. We identified 5560 incident cases of RA and 22,800 matched general population controls. Characteristics of the cohorts at the time of 
$\mathbf{1 A}$

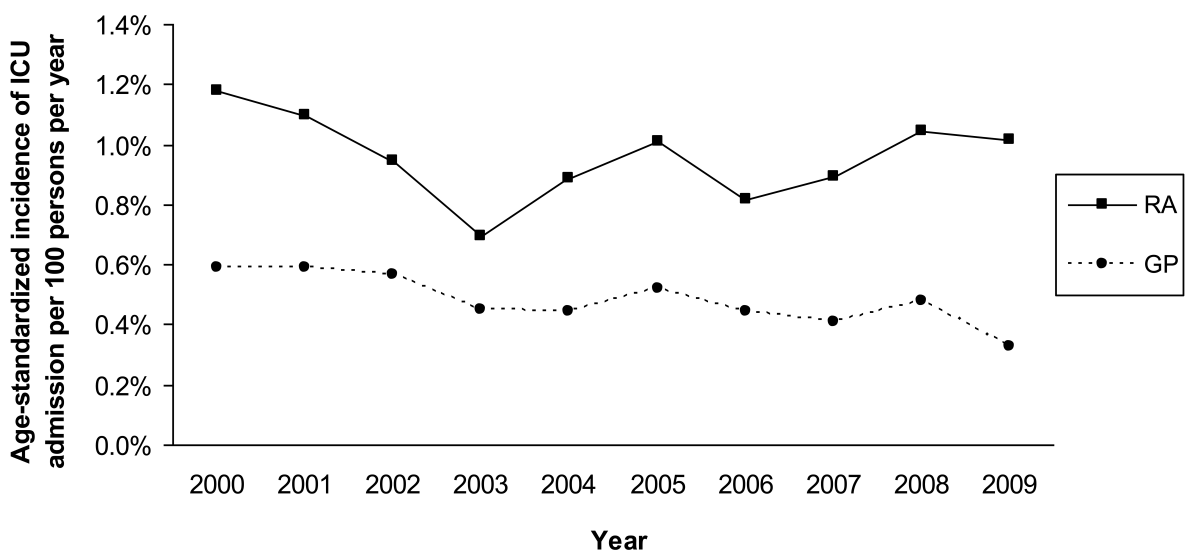

$1 \mathbf{B}$

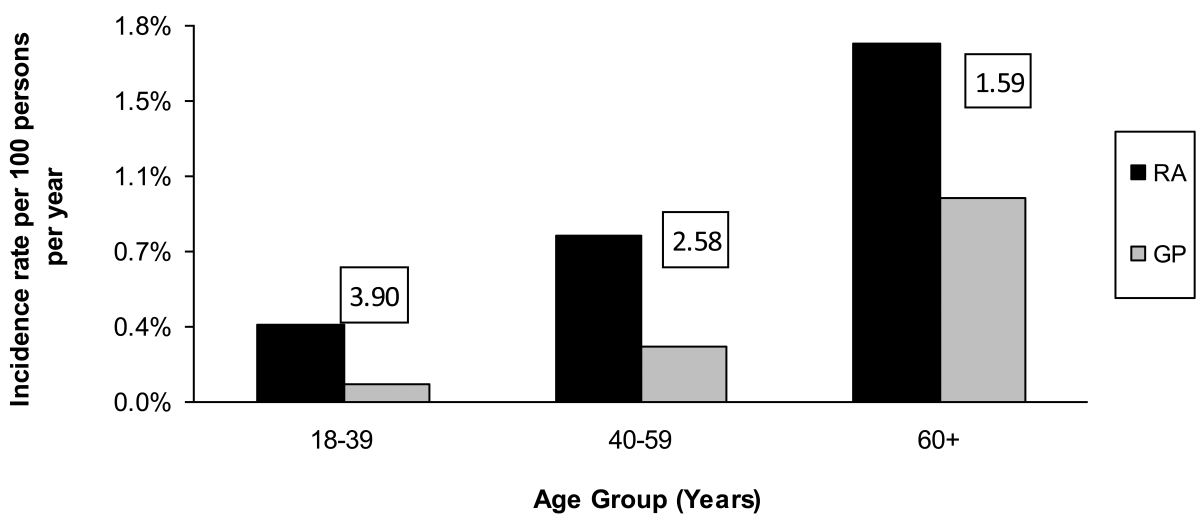

Figure 1. (A) Age-standardized annual incidence of ICU admission and (B) average annual age-specific incidence rates among prevalent cases of RA and matched GP controls. Boxes above GP bars show incidence rate ratios comparing incidence of ICU admission by age group in RA compared with GP. RA: rheumatoid arthritis; GP: general population; ICU: intensive care unit.

diagnosis of RA (or index date for the matched control) are shown in Table 1. At the time of diagnosis, persons with RA already had significantly more comorbidity compared with the matched general population cohort, with $14 \%$ of patients with RA having additional comorbid conditions compared with $8 \%$ of the matched cohort $(\mathrm{p}<0.001)$.

Of the 5560 incident cases of RA, 507 (9.1\%) were admitted to ICU versus only $1477(5.1 \%)$ of matched controls. Mean disease duration at time of the first ICU admission was just under 6 years (median $4.6 \mathrm{yrs}$ ), and patients with RA were on average 2 years younger than controls at ICU admission ( $\mathrm{p}=0.0022$ ). While comorbidity had increased since the index date in both groups, only $13 \%$ of patients with RA had no comorbid conditions $(\mathrm{CCI}=0)$ at the time of ICU admission compared with $22 \%$ of matched controls ( $p<0.001)$. Using Kaplan-Meier analysis, the ICU admission risk was increased in persons with RA as compared with the general population (log-rank chi-square $=387.2, \mathrm{p}<0.0001)$. In the multivariable model, the hazard of ICU admission was elevated for RA (HR 1.65, 95\% CI 1.50-1.83) after adjusting for age, sex, SES, and comorbidity. The risk of ICU admission declined in those with shorter disease duration compared with those diagnosed earlier (Table 2). In a separate age-stratified analysis, the risk of ICU admission was higher in all age groups; however, the risk was highest in persons with RA under the age of 40, who had a greater than 3-fold increase (HR 3.46, 95\% CI 2.39-5.01) compared with the age-matched general population. HR were similar for persons aged 40-59 (HR 1.55; 95\% CI: 1.29-1.86) and persons aged 60 years and older (HR 1.48; 95\% CI: 1.31-1.67).

Reasons for ICU admission in incident cohorts. For the subset of patients with incident RA admitted to the ICU from 2000-2010, where clinical data were available (343/507 incident patients included in the ICU database, 68\%), we compared clinical characteristics at first ICU admission between the incident RA population and the general population (Table 3 ). In the RA population, a higher proportion of

Personal non-commercial use only. The Journal of Rheumatology Copyright (C) 2016. All rights reserved. 
Table 3. Characteristics of the incident RA and general population cohorts at the first ICU admission in the Winnipeg Regional Health Authority in the interval 2000-2010*. Values are mean (SD) unless otherwise specified.

\begin{tabular}{|c|c|c|c|}
\hline Characteristic & $\begin{array}{l}\text { General Population } \\
\text { Controls, } \mathrm{n}=853\end{array}$ & $\mathrm{RA}, \mathrm{n}=343$ & $\mathrm{p}$ \\
\hline Female, $\mathrm{n}(\%)$ & $482(56.5)$ & $223(65.0)$ & 0.0068 \\
\hline Age at admission, yrs & $70.3(11.9)$ & $67.1(13.1)$ & 0.0003 \\
\hline Duration of followup from the index date, yrs & $7.56(4.9)$ & $7.43(4.8)$ & 0.68 \\
\hline ICU length of stay, days & $4.23(6.8)$ & $4.94(11.1)$ & 0.088 \\
\hline Hospital length of stay, days & $23.6(39.6)$ & $26.4(41.1)$ & 0.072 \\
\hline APACHE II Acute Physiology Score & $10.8(6.9)$ & $11.0(6.89)$ & 0.46 \\
\hline Glasgow Coma Score, median (IQR) & $15(15-15)$ & $15(15-15)$ & 0.17 \\
\hline Mechanical ventilation, n (\%) & $380(44.5)$ & $159(46.4)$ & 0.57 \\
\hline Vasoactive agents, $\mathrm{n}(\%)$ & $336(39.4)$ & $134(39.1)$ & 0.92 \\
\hline Dialysis, n (\%) & $34(4.0$ & $9(2.6)$ & 0.25 \\
\hline \multicolumn{4}{|l|}{ Region of residence, n (\%) } \\
\hline Urban & $548(64.2)$ & $225(65.6)$ & 0.65 \\
\hline Socioeconomic status, n (\%) & & & 0.36 \\
\hline Rural 1, lowest rural & $62(7.3)$ & $29(8.4)$ & \\
\hline Rural 2 & $66(7.7)$ & $21(6.1)$ & \\
\hline Rural 3 & $57(6.7)$ & $30(8.7)$ & \\
\hline Rural 4 & $67(7.8)$ & $* *$ & \\
\hline Rural 5, highest rural & $43(5.0)$ & $21(6.1)$ & \\
\hline Urban 1 , lowest urban & $140(16.4)$ & $64(18.6)$ & \\
\hline Urban 2 & $127(14.9)$ & $50(14.6)$ & \\
\hline Urban 3 & $129(15.1)$ & $44(12.8)$ & \\
\hline Urban 4 & $84(9.8)$ & $30(8.7)$ & \\
\hline Urban 5, highest urban & $64(7.5)$ & $34(9.9)$ & \\
\hline Not calculated* & $14(1.6)$ & $* *$ & \\
\hline \multicolumn{4}{|l|}{ Modified Charlson Comorbidity Index, n (\%) } \\
\hline 0 & $162(19.0)$ & $46(13.4)$ & 0.039 \\
\hline 1 & $217(25.4)$ & $90(26.2)$ & \\
\hline$>1$ to 3 & $327(38.3)$ & $134(39.1)$ & \\
\hline$>3$ & $147(17.2)$ & $73(21.3)$ & \\
\hline
\end{tabular}

* Note that because of matching on the index date of diagnosis with RA, the cohorts are no longer matched by the time of first ICU admission, and $\mathrm{n}$ are smaller here than in Supplementary Table 3 (available online at jrheum.org) as reasons for admission available only in Winnipeg for the period 2000-2010. ** Suppressed because of small cell size to protect confidentiality. RA: rheumatoid arthritis; ICU: intensive care unit; APACHE: Acute Physiology and Chronic Health Evaluation; IQR: interquartile range.

women were admitted to the ICU compared with the general population. Patients with RA were also younger at ICU admission and had slightly higher mCCI scores. There were no differences in the length of ICU or entire hospital stay, APS, GCS, or use of life support measures. The most common reason for admission in RA was IHD (45.8\%), followed by infection (19.8\%) and respiratory system disease (6.7\%; Table 4). Six patients with RA were admitted to ICU following complications of arthroplasty surgery; of these, 1 had a cardiac arrest resulting in admission.

Compared with the general population, the RA population was more likely to be admitted for an infection even after accounting for potential confounders of age, sex, region of residence, SES, disease duration, $\mathrm{mCCI}$, and year of ICU admission (OR 1.74, 95\% CI 1.30-2.31; Supplementary Table 3 available online at jrheum.org). Therefore, we evaluated the association of therapy with admission for infection initially as any immunosuppressive or immunomod- ulatory drug, and then divided into corticosteroids and immunomodulatory and immunosuppressive therapies (Supplementary Table 2 available online at jrheum.org). After adjusting for any therapy, the association of RA with infection was no longer statistically significant; however, corticosteroid use was strongly associated with the ICU admission for infection (OR 1.97, 95\% CI 1.53-2.52) while other therapies were not. The RA population was also more likely to be admitted to ICU for IHD (OR 1.71, 95\% CI 1.09-2.70), after adjusting for the same potential covariates including therapy. However, corticosteroid or other immunomodulatory therapy was not associated with ICU admission for IHD.

Mortality after ICU admission. Mortality within 1 year after ICU admission was somewhat elevated in RA (RR 1.35, 95\% CI 0.99-1.75; Table 5). This appeared to be driven by increased mortality in patients over age 40 years. Cause of death for patients with RA who died within 1 year post-ICU

Personal non-commercial use only. The Journal of Rheumatology Copyright $\subset$ 2016. All rights reserved. 
Table 4. Reasons for first intensive care unit admission among incident cohort of RA. Values are n (\%).

\begin{tabular}{|c|c|c|}
\hline Reason & $\begin{array}{l}\text { General Population } \\
\text { Controls, } \mathrm{n}=5349 *\end{array}$ & $\mathrm{RA}, \mathrm{n}=343$ \\
\hline Ischemic cardiovascular disease $* *$ & $2535(47.4)$ & $157(45.8)$ \\
\hline Infection & $648(12.1)$ & $68(19.8)$ \\
\hline All other ${ }^{\dagger}$ & $2166(40.5)$ & $118(34.4)$ \\
\hline Respiratory system & $292(5.4)$ & $23(6.7)$ \\
\hline $\begin{array}{l}\text { Injury and poisoning, including } \\
\text { self-harm }\end{array}$ & $222(4.2)$ & $20(5.89)$ \\
\hline $\begin{array}{l}\text { Symptoms, signs, and ill-defined } \\
\text { conditions }\end{array}$ & $311(5.9)$ & $14(4.1)$ \\
\hline Circulatory system ${ }^{\ddagger}$ & $1072(20.0)$ & $9(2.6)$ \\
\hline Diseases of the digestive system & $140(2.6)$ & $9(2.6)$ \\
\hline Miscellaneous & $129(2.4)$ & $43(12.5)$ \\
\hline
\end{tabular}

* Matches drawn each year from 2000 through 2010. ** Myocardial infarctions, unstable angina, acute coronary insufficiency, and angioplasty or coronary artery bypass grafting. ${ }^{\dagger}$ Categories of "other" reasons for admission also subdivided by International Classification of Disease chapters for categories affecting $\geq 5 \%$ of either study cohort. $\$$ Cerebrovascular accidents, arrhythmias, valve replacement surgery, and congestive heart failure without documentation of ischemic heart disease were included under other diseases of the circulatory system. RA: rheumatoid arthritis.

admission included diseases of the circulatory system (26\%), malignancy (12\%), infection (8\%), and RA (8\%), with the remaining $46 \%$ reported as other causes.

\section{DISCUSSION}

Critical illness was common in our RA population. Nearly $1 \%$ of adults required ICU admission each year with a 10 -year cumulative incidence of critical illness of more than $8 \%, 60 \%$ higher than in the general population. To our knowledge, there are no prior studies evaluating the risk of ICU admission in RA, so we cannot draw comparisons. While the risk of ICU admission increased steadily with age, the excess risk was greatest in the youngest age group; patients with RA under 40 years had a more than 3 -fold greater risk of ICU admission, emphasizing the potential severity of RA, even in a younger population.

Persons with RA admitted to the ICU in our study had more comorbidity than the general population, even at the time of diagnosis corresponding to the very high frequency of comorbidity described for patients with $\mathrm{RA}^{40}$. Because RA is rarely the direct cause of hospitalization or mortality, it is assumed that this comorbidity frequently led to the ICU admissions. Mean disease duration at the time of first ICU admission was only 6 years in patients with RA, suggesting a relatively rapid accumulation of comorbidities, rather than a slow accrual over decades. Other studies also have shown increased comorbidities early in the course of $\mathrm{RA}^{41,42}$.

Consistent with the known association of IHD with RA, IHD was the most common comorbidity resulting in ICU admission, accounting for almost half of the admissions in patients with RA. An additional $7.6 \%$ were related to other diseases of the circulatory system. IHD is known to account for at least $50 \%$ of premature deaths in $\mathrm{RA}^{43}$. We did not find an association between corticosteroids and ICU admission for IHD, although this does not preclude an overall association between corticosteroids and the development of IHD in RA, which was not a focus of our analysis.

Infection was a frequent reason for ICU admission in RA, with a $70 \%$ increased risk of ICU admission for infection compared with the general population. Interestingly, after adjusting for drug therapy, the association between infection and ICU admission in RA was no longer significant. However, when corticosteroid therapy was analyzed separately from other immunomodulatory therapy, corticosteroids completely explained this added risk with an almost 2 -fold increase. This suggests that corticosteroids, but not immunomodulatory therapies, were the main driver of increased infection risk in RA. Overall, there is a paucity of data on corticosteroids and the risk of infection in RA with inconclusive results ${ }^{15,17,18}$. To our knowledge, this is the first population-based study to demonstrate the contribution of steroids to serious infection resulting in critical illness in RA.

Table 5. Mortality rates $(95 \% \mathrm{CI})$ after first ICU admission in RA, and percentage-specific mortality 1 year after ICU admission in RA as compared with the matched cohort from the general population.

\begin{tabular}{lccc}
\hline Variables & $\begin{array}{c}\text { General Population } \\
\text { Controls, Mortality (95\% CI) }\end{array}$ & $\begin{array}{c}\text { RA, Mortality } \\
(95 \% \mathrm{CI})\end{array}$ & $\begin{array}{c}\text { Rate Ratio* } \\
\text { (95\% CI) }\end{array}$ \\
\hline $\begin{array}{l}\text { Mortality timepoint } \\
\quad \text { ICU }\end{array}$ & $9.10(8.40-9.85)$ & $11.3(8.82-13.8)$ & $1.18(0.64-1.88)$ \\
$\quad$ Hospital & $16.0(15.1-16.9)$ & $19.4(16.6-23.0)$ & $1.31(0.87-1.81)$ \\
$\quad$ 30 days after ICU admission & $14.2(13.3-15.1)$ & $16.5(13.5-19.4)$ & $1.24(0.78-1.78)$ \\
$\quad \begin{array}{l}\text { 1 yr after ICU admission } \\
\text { Age group, yrs }\end{array}$ & $22.4(21.4-23.5)$ & $29.2(25.6-32.9)$ & $1.35(0.99-1.75)$ \\
$\quad<40$ & $9.1(6.46-11.69)$ & $21.0(2.72-39.4)$ & $2.32(0.48-4.96)$ \\
$\quad 40-59$ & $11.74(10.65-12.84)$ & $20.8(13.8-27.7)$ & $1.77(1.19-2.39)$ \\
$\geq 60$ & $23.85(22.95-24.74)$ & $32.1(27.7-36.4)$ & $1.34(1.17-1.53)$ \\
\hline
\end{tabular}

* Comparison is to age- and sex-matched general population cohorts. RA: rheumatoid arthritis; ICU: intensive care unit. 
Because of small numbers, we could not analyze biologic therapies separately from other therapies (only $~ 15 \%$ of prevalent patients with RA were receiving biologic therapy by 2010$)^{33}$, but while this is not conclusive, our analysis does not support a significant added risk of serious infection with newer therapies.

The risk of critical illness was overall higher in men. Even though, typical of RA, 73\% of the RA cohort were women, only $65 \%$ of those patients with RA admitted to the ICU were women. This may relate to a higher overall risk of CVD in men: men had a 50\% higher risk of any critical illness (Table 2), but this risk increased to an adjusted OR of 1.8 (95\% CI 1.6-2.1) for those patients admitted for IHD. While RA has been reported to be more severe in women ${ }^{44}$, some but not all studies show higher mortality in men ${ }^{42,45}$. Critical illness, particularly because of IHD, may be a contributing factor to increased mortality for men with RA.

We also found that people with RA had $40 \%$ higher mortality at 1 year after ICU admission, but did not have higher rates of death in the ICU, in the hospital, or at 30 days. In RA, median survival is reduced by 10 years, with a standardized mortality ratio of greater than $2.0^{46}$. While hospital mortality has been reported to be higher after ICU admission among persons with all rheumatic diseases compared with the general population ${ }^{26}$, this has not been evaluated in RA specifically. Prior studies of the causes, clinical features, and outcomes of patients with RA requiring ICU admission combined multiple autoimmune rheumatic diseases ${ }^{23,24,25,26}$, making comparisons difficult. We have previously reported a similar increased risk of death following ICU admission in multiple sclerosis and inflammatory bowel disease ${ }^{35,36}$. Circulatory disease was the single most common cause of death, not surprisingly, because CVD is known to be the most common cause of death in $\mathrm{RA}^{4}$.

Our study had several strengths. The study was population-based, and novel; the first, to our knowledge, to describe the high risk of critical illness in RA. We estimated the incidence of ICU admission among persons with incident and prevalent RA, carefully described the characteristics of their critical illness, and accounted for multiple confounders. However, we lacked data regarding the clinical characteristics of RA, including disease-specific severity measures, and thus could not evaluate how those factors influenced the risk of ICU admission. Greater disease severity, requiring greater use of corticosteroids, may have been involved in our finding of corticosteroid use increasing the risk of critical illness. We also found that those patients with a more recent RA diagnosis had a lower risk of ICU admission, even after adjusting for age and mCCI, compared with those with more longstanding disease. This may reflect incomplete ascertainment of comorbidity, but may also reflect the declining severity of the RA phenotype ${ }^{47}$. Similarly, we lacked data on some traditional risk factors for CVD. Smoking may be particularly important, given the known increased risk of RA in smokers ${ }^{48,49}$; it may be that there were more smokers in the RA population. Administrative data may suffer from clinically imprecise coding. However, we have established the validity of these data for identifying episodes of ICU care, as well as for RA; the definition for RA produces the expected prevalence in Manitoba of $0.5 \% \%^{30,33}$.

Our study demonstrated high rates of critical illness and increased mortality following ICU admission in patients with RA, illustrating that RA remains a serious illness in spite of advances in therapy. Continued attention is required to managing and reducing comorbidity, particularly prevention and management of CVD and infection.

\section{ACKNOWLEDGMENT}

The authors acknowledge the Manitoba Centre for Health Policy for use of data contained in the Population Health Research Data Repository under project \#2010-013 (HIPC\#2010/11-15A).

\section{ONLINE SUPPLEMENT}

Supplementary data for this article are available online at jrheum.org.

\section{REFERENCES}

1. Health Canada. Arthritis in Canada: an ongoing challenge. [Internet. Accessed October 26, 2015.] Available from: www.acreu.ca/pdf/Arthritis_in_Canada.pdf

2. Gullick NJ, Scott DL. Co-morbidities in established rheumatoid arthritis. Best Pract Res Clin Rheumatol 2011;25:469-83.

3. Myasoedova E, Crowson CS, Nicola PJ, Maradit-Kremers H, Davis JM 3rd, Roger VL, et al. The influence of rheumatoid arthritis disease characteristics on heart failure. J Rheumatol 2011; 38:1601-6.

4. Sokka T, Abelson B, Pincus T. Mortality in rheumatoid arthritis: 2008 update. Clin Exp Rheumatol 2008;26 Suppl 51:S35-61.

5. Kalkan A, Hallert E, Bernfort L, Husberg M, Carlsson P. Costs of rheumatoid arthritis during the period 1990-2010: a register-based cost-of-illness study in Sweden. Rheumatology 2014;53:153-60.

6. Ohinmaa AE, Thanh NX, Barnabe C, Martin L, Russell AS, Barr $\mathrm{SG}$, et al. Canadian estimates of health care utilization costs for rheumatoid arthritis patients with and without therapy with biologic agents. Arthritis Care Res 2014;66:1319-27.

7. da Rocha Castelar Pinheiro G, Khandker RK, Sato R, Rose A, Piercy J. Impact of rheumatoid arthritis on quality of life, work productivity and resource utilisation: an observational, cross-sectional study in Brazil. Clin Exp Rheumatol 2013; 31:334-40

8. Michaud K, Messer J, Choi HK, Wolfe F. Direct medical costs and their predictors in patients with rheumatoid arthritis: a three-year study of 7,527 patients. Arthritis Rheum 2003;48:2750-62.

9. Boonen A, Severens JL. The burden of illness of rheumatoid arthritis. Clin Rheumatol 2011;30 Suppl 1:S3-8.

10. Wright K, Crowson CS, Gabriel SE. Cardiovascular comorbidity in rheumatic diseases: a focus on heart failure. Heart Fail Clin 2014;10:339-52.

11. Wolfe F, Michaud K. The risk of myocardial infarction and pharmacologic and nonpharmacologic myocardial infarction predictors in rheumatoid arthritis: a cohort and nested case-control analysis. Arthritis Rheum 2008;58:2612-21.

12. Troelsen LN, Garred P, Jacobsen S. Mortality and predictors of mortality in rheumatoid arthritis - a role for mannose-binding lectin? J Rheumatol 2010;37:536-43.

13. Koivuniemi R, Paimela L, Leirisalo-Repo M. Causes of death in patients with rheumatoid arthritis from 1971 to 1991 with special

Personal non-commercial use only. The Journal of Rheumatology Copyright @ 2016 . All rights reserved. 
reference to autopsy. Clin Rheumatol 2009;28:1443-7.

14. Resman-Targoff BH, Cicero MP. Aggressive treatment of early rheumatoid arthritis: recognizing the window of opportunity and treating to target goals. Am J Manag Care 2010;16 Suppl:S249-58.

15. Dixon WG, Suissa S, Hudson M. The association between systemic glucocorticoid therapy and the risk of infection in patients with rheumatoid arthritis: systematic review and meta-analyses. Arthritis Res Ther 2011;13:R139.

16. Furst DE. The risk of infections with biologic therapies for rheumatoid arthritis. Semin Arthritis Rheum 2010;39:327-46.

17. Ruyssen-Witrand A, Fautrel B, Saraux A, Le-Loët X, Pham T. Infections induced by low-dose corticosteroids in rheumatoid arthritis: a systematic literature review. Joint Bone Spine 2010;77:246-51

18. Listing J, Gerhold K, Zink A. The risk of infections associated with rheumatoid arthritis, with its comorbidity and treatment. Rheumatology 2013;52:53-61.

19. Sizova L. Approaches to the treatment of early rheumatoid arthritis with disease-modifying antirheumatic drugs. Br J Clin Pharmacol 2008;66:173-8.

20. Galloway JB, Hyrich KL, Mercer LK, Dixon WG, Ustianowski AP, Helbert M, et al; BSR Biologics Register. Risk of septic arthritis in patients with rheumatoid arthritis and the effect of anti-TNF therapy: results from the British Society for Rheumatology Biologics Register. Ann Rheum Dis 2011;70:1810-4.

21. Greenberg JD, Reed G, Kremer JM, Tindall E, Kavanaugh A, Zheng $\mathrm{C}$, et al; CORRONA Investigators. Association of methotrexate and tumour necrosis factor antagonists with risk of infectious outcomes including opportunistic infections in the CORRONA registry. Ann Rheum Dis 2010;69:380-6.

22. Dedhia H, DiBartolomeo A. Rheumatoid arthritis. Crit Care Clin 2002;18:841-54.

23. Janssen NM, Karnad DR, Guntupalli KK. Rheumatologic diseases in the intensive care unit: epidemiology, clinical approach, management, and outcome. Crit Care Clin 2002;18:729-48.

24. Godeau B, Boudjadja A, Dhainaut JF, Schlemmer B, Chastang C, Brunet F, et al. Outcome of patients with systemic rheumatic disease admitted to medical intensive care units. Ann Rheum Dis 1992;51:627-31

25. Ozbalkan Z, Topeli A, Kiraz S, Ozturk MA, Ertenli I, Calguneri M. The contribution of underlying systemic rheumatic diseases to the mortality in patients admitted for intensive care: a matched cohort study. Clin Exp Rheumatol 2004;22:223-6.

26. Thong BY, Tai DY, Goh SK, Johan A. An audit of patients with rheumatic disease requiring medical intensive care. Ann Acad Med Singapore 2001;30:254-9.

27. Health Information Management Branch. Population report. Winnipeg: Manitoba Health and Healthy Living; 2009.

28. Haupt MT, Bekes CE, Brilli RJ, Carl LC, Gray AW, Jastremski MS, et al; Task Force of the American College of Critical Care Medicine, Society of Critical Care Medicine. Guidelines on critical care services and personnel: recommendations based on a system of categorization of three levels of care. Crit Care Med 2003; 31:2677-83

29. Garland A, Fransoo R, Olafson K, Ramsey C, Yogendran M, Chateau D, et al. The Epidemiology and outcomes of critical illness in Manitoba. [Internet. Accessed October 26, 2015.] Available from: mchp-appserv.cpe.umanitoba.ca/reference/MCHP ICU_Report_WEB_(20120403).pdf

30. Garland A, Yogendran M, Olafson K, Scales DC, McGowan KL, Fransoo R. The accuracy of administrative data for identifying the presence and timing of admission to intensive care units in a Canadian province. Med Care 2012;50:e1-6.
31. Knaus WA, Wagner DP, Draper EA, Zimmerman JE, Bergner M, Bastos PG, et al. The APACHE III prognostic system. Risk prediction of hospital mortality for critically ill hospitalized adults. Chest 1991;100:1619-36.

32. Teasdale G, Jennett B. Assessment of coma and impaired consciousness. A practical scale. Lancet 1974;2:81-4.

33. Peschken C, Hitchon C, Chen H, Garland A, El-Gabalawy H, Bernstein $\mathrm{C}$, et al. Administrative definitions of rheumatoid arthritis: rising prevalence regardless of definition used. Arthritis Rheum 2011;63:S1009.

34. Sun J, Gooch K, Svenson LW, Bell NR, Frank C. Estimating osteoarthritis incidence from population-based administrative health care databases. Ann Epidemiol 2007;17:51-6.

35. Marrie RA, Bernstein CN, Peschken CA, Hitchon CA, Chen H, Fransoo R, et al. Intensive care unit admission in multiple sclerosis: increased incidence and increased mortality. Neurology 2014;82:2112-9.

36. Marrie RA, Garland A, Peschken CA, Hitchon CA, Chen H, Fransoo R, et al. Increased incidence of critical illness among patients with inflammatory bowel disease: a population-based study. Clin Gastroenterol Hepatol 2014;12:2063-70.

37. Needham DM, Scales DC, Laupacis A, Pronovost PJ. A systematic review of the Charlson comorbidity index using Canadian administrative databases: a perspective on risk adjustment in critical care research. J Crit Care 2005;20:12-9.

38. Preen DB, Holman CD, Spilsbury K, Semmens JB, Brameld KJ. Length of comorbidity lookback period affected regression model performance of administrative health data. J Clin Epidemiol 2006;59:940-6.

39. Camargo JF, Tobon GJ, Fonseca N, Diaz JL, Uribe M, Molina F, et al. Autoimmune rheumatic diseases in the intensive care unit: experience from a tertiary referral hospital and review of the literature. Lupus 2005;14:315-20.

40. Wasko MC. Comorbid conditions in patients with rheumatic diseases: an update. Curr Opin Rheumatol 2004;16:109-13.

41. Kremers HM, Crowson CS, Therneau TM, Roger VL, Gabriel SE. High ten-year risk of cardiovascular disease in newly diagnosed rheumatoid arthritis patients: a population-based cohort study. Arthritis Rheum 2008;58:2268-74.

42. Young A, Koduri G. Extra-articular manifestations and complications of rheumatoid arthritis. Best Pract Res Clin Rheumatol 2007;21:907-27.

43. Symmons DP, Gabriel SE. Epidemiology of CVD in rheumatic disease, with a focus on RA and SLE. Nat Rev Rheumatol 2011;7:399-408.

44. Symmons D, Turner G, Webb R, Asten P, Barrett E, Lunt M, et al. The prevalence of rheumatoid arthritis in the United Kingdom: new estimates for a new century. Rheumatology 2002;41:793-800

45. Anderson ST. Mortality in rheumatoid arthritis: do age and gender make a difference? Semin Arthritis Rheum 1996;25:291-6.

46. Minaur NJ, Jacoby RK, Cosh JA, Taylor G, Rasker JJ. Outcome after 40 years with rheumatoid arthritis: a prospective study of function, disease activity, and mortality. J Rheumatology Suppl 2004 Mar;69:3-8.

47. Verstappen SM, Symmons DP. What is the outcome of RA in 2011 and can we predict it? Best Pract Res Clin Rheumatol 2011; 25:485-96.

48. Hoovestol RA, Mikuls TR. Environmental exposures and rheumatoid arthritis risk. Curr Rheumatol Rep 2011;13:431-9.

49. Klareskog L, Malmström V, Lundberg K, Padyukov L, Alfredsson L. Smoking, citrullination and genetic variability in the immunopathogenesis of rheumatoid arthritis. Semin Immunol 2011;23:92-8 